\title{
Multi-Scale Structure Construction by Layer-by-Layer Self-Assembly to Modify the Carbon Fiber Surface
}

Jingbiao Liu, ${ }^{\mathrm{a}, \mathrm{b}}$ Benzhi Min, ${ }^{\mathrm{a}}$ Zhenqing Wang, ${ }^{\mathrm{a}}{ }^{*}$ Shuzhou Li ${ }^{*}$

${ }^{a}$ College of Aerospace and Civil Engineering, Harbin Engineering University,

Harbin, P. R. China

${ }^{\mathrm{b}}$ School of Materials Science and Engineering, Nanyang Technological University,

Singapore 639798, Singapore

*Corresponding author: wangzhenqing@hrbeu.edu.cn, lisz@ntu.edu.sg

\section{Supporting Information}

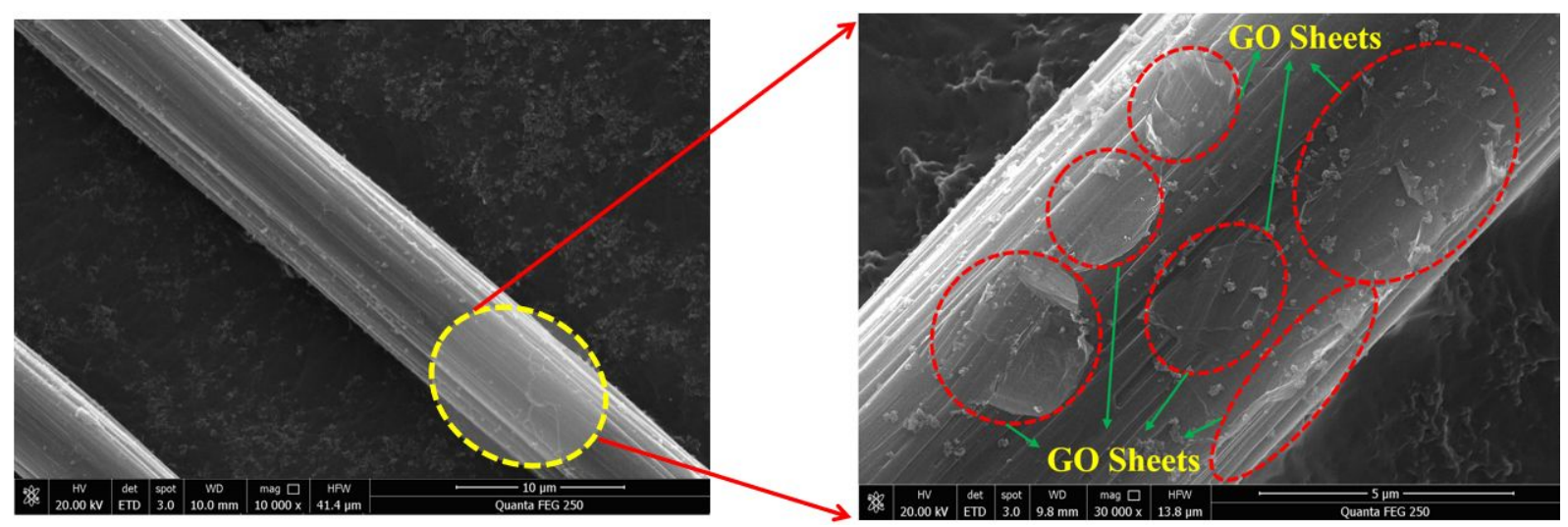

Figure S1. SEM image at another angle of CF-L1 


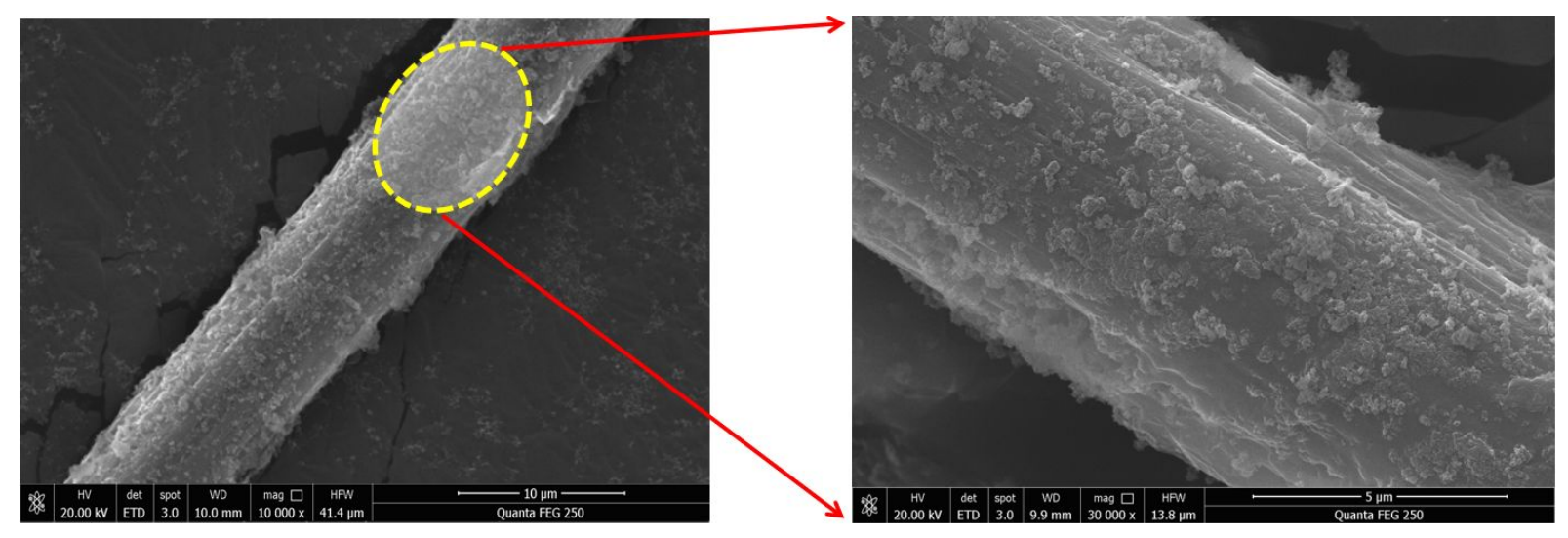

Figure S2. SEM image at another angle of CF-L5 